\title{
Associations between TLR4 Polymorphisms and Open Angle Glaucoma: A Meta-Analysis
}

\author{
Zhongjing Lin $\mathbb{D}^{\mathbb{D}}$, Shouyue Huang, Jun Sun, Bing Xie $\mathbb{D}$, and Yisheng Zhong $\mathbb{1}$ \\ Department of Ophthalmology, Ruijin Hospital Affiliated Medical School, Shanghai Jiaotong University, \\ 197 Ruijin Er Road, 200025 Shanghai, China \\ Correspondence should be addressed to Bing Xie; brinkleybing@126.com and Yisheng Zhong; yszhong68@126.com
}

Received 30 January 2019; Revised 26 June 2019; Accepted 14 July 2019; Published 24 July 2019

Academic Editor: Susmito Biswas

Copyright (C) 2019 Zhongjing Lin et al. This is an open access article distributed under the Creative Commons Attribution License, which permits unrestricted use, distribution, and reproduction in any medium, provided the original work is properly cited.

Background. Previous studies exploring the association between toll-like receptor 4 (TLR4) polymorphisms and open angle glaucoma (OAG) presented inconsistent results. We aimed to investigate the association between TLR4 polymorphisms and OAG. Methods. A systematic literature search was conducted in PubMed, EMBASE, ISI Web of Knowledge, and the Cochrane Library up to 31 December 2018. Odds ratio (OR) and 95\% confidence interval (95\%CI) were calculated, followed by stratification analyses according to ethnicity and glaucoma subtype. Results. TLR4 rs7037117 polymorphism had significant associations with increased risk of OAG in allelic model $(\mathrm{OR}=1.25 ; 95 \% \mathrm{CI}$ : 1.09-1.44; $\mathrm{P}=0.002)$ and recessive model (OR=1.49; 95\%CI: 1.08-2.04; $\mathrm{P}=0.01)$. With regard to rs10759930, rs12377632, and rs2149356, the results showed significant increased risks in all genetic models (all $\mathrm{P}<0.05)$, whereas, for rs1927914, rs11536889, and rs7045953, no significant associations were identified in any genetic model (all $\mathrm{P}>0.05$ ). Furthermore, the association of rs1927911 with OAG risk was found to be significant in recessive model (OR=1.34; 95\%CI: 1.06-1.71; $\mathrm{P}=0.02$ ). As for rs 4986790 and rs4986791, meta-analyses were not performed due to the limited number of studies and the ethnic differences. Subgroup analysis indicated that the above polymorphisms with significant differences might increase the susceptibility in POAG patients. As for the ethnicity, rs7037117, rs10759930, and rs1927911 might increase the risk in Asians, while rs12377632 and rs2149356 might increase the risk in Asians and Mexicans. Conclusion. The meta-analysis highlighted that certain mutations of some TLR4 polymorphisms might increase the susceptibility of OAG. However, TLR4 polymorphisms are still far from being candidate genetic biomarkers for OAG. Additional researches involving larger scale epidemiological studies are warranted to validate our results.

\section{Introduction}

Glaucoma is a group of neurodegenerative diseases that can lead to irreversible blindness. The total amount of glaucomatous patients aged $40-80$ years was estimated to be 64.3 million in 2013, and it will dramatically increase to 111.8 million in 2040 [1]. Open angle glaucoma (OAG) is the most common form, accounting for about $85 \%$ of glaucoma cases. It is characterized by progressive degeneration of retinal ganglion cells (RGCs) and subsequent irrevocable vision loss, which can occur with either elevated intraocular pressure (IOP) or normal IOP, commonly termed as primary open-angle glaucoma (POAG) and normal tension glaucoma (NTG), respectively. The precise pathophysiology of OAG is complex and the mechanism remains obscure. Despite the major risk factor of increased IOP, genetic variations also play an important role in this disease profile [2]. Mutations in various genes have been reported in glaucoma patients from multiple populations [3-5]. Therefore, close attention has been paid to the association between single-nucleotide polymorphisms (SNPs) of genes and the development of OAG.

It has been reported that the immune regulation is involved in the pathogenesis of the degeneration of the RGCs in glaucoma $[6,7]$. One of the key proteins in the immune response is toll-like receptors (TLRs) [8]. TLRs have been recognized as a family of pattern-recognition receptors and have a specific role in the human immune systems. TLR4, one of the most characterized members in the TLR family, has been reported to recognize lipopolysaccharides (LPS) and heat shock proteins (HSP), initiating immune responses that interact with exogenous and endogenous ligands. TLR4 has 
been demonstrated to affect the risk of various multifactorial disorders, such as retinal ischemia/reperfusion injury, glaucoma, and diabetic retinopathy [9]. In in vivo studies, the results suggested that the inhibition of TLR4 signaling might be a promising candidate for the treatment of glaucoma [1012]. Moreover, prior investigations revealed an upregulation of TLRs in the glaucomatous human retina by proteomic and immunohistochemical analyses, and in vitro findings in retinal microglia and astrocytes cultures suggested a TLRmediated response leading to increased cytokine production and antigen presentation, indicating that TLRs play a role modulating the immune response in glaucoma [13].

In the past decades, several case-control studies varying in design, ethnicity, and sample size are examining the potential association between TLR4 polymorphisms and glaucoma, only to find inconclusive or contradictory results [14-21]. For example, Takano et al. [16] concluded that TLR4 polymorphisms were associated with POAG and NTG patients in Japanese individuals. However, Suh et al. [15] demonstrated that TLR4 polymorphisms may not be an associated factor in NTG pathogenesis in the South Korean population. Mousa et al. [18] indicated that there were no obvious associations between TLR4 rs4986791 and POAG in a Saudi cohort. Therefore, we aimed to investigate the possible association between TLR4 polymorphisms and OAG using a meta-analysis approach, followed by stratification analyses according to ethnicity and the subtype of glaucoma.

\section{Materials and Methods}

2.1. Literature Search. The review searching process conformed to the Preferred Reporting Items for Systematic Reviews and Meta-Analyses (PRISMA) guidelines. We performed a literature search using PubMed, EMBASE, ISI Web of Knowledge, and the Cochrane Library without language or time restrictions. The final search was conducted on 31 December 2018. We searched the databases using the following key words in different combinations: toll-like receptor, polymorphism, and glaucoma. Furthermore, the reference lists of the relevant publications were also checked carefully to identify any additional study not found through electronic searching.

2.2. Inclusion and Exclusion Criteria. Eligible studies were selected if they were case-control studies which evaluated the association between TLR4 polymorphisms and OAG and presented the distributions of TLR4 alleles for both cases and controls. All animal studies, case reports, abstracts from conferences, studies with incomplete data, and reviews were excluded. Although we did not define language in the review process, the articles in the final analysis were all in English.

2.3. Data Extraction. Two review authors extracted all the required data independently from the included articles. The extracted information included the following: first author, publication year, country, number of cases and controls, and genotype frequencies for cases and controls. Divergences, if existed, would be eliminated by discussion.
2.4. Quality Assessment. The Newcastle-Ottawa Scale (NOS) was used for the quality assessment in our meta-analysis. This quality scoring system contains three broad perspectives, divided into 8 items specifically, and the total score ranges as zero up to nine stars [22]. A score of 6 or higher indicates that the study has adequate quality. Two review authors subjectively scored each involved study and any differences would be resolved by discussion if applicable.

2.5. Statistical Analysis. Statistical analysis was performed using Revman software (version 5.3; Cochrane Collaboration, Oxford, United Kingdom). If the Hardy-Weinberg Equilibrium (HWE) was not reported in the original papers, we would calculate HWE p-value for the control group of each study using the Chi-square test, and p-value $<0.05$ was defined as a significant disequilibrium. We examined the heterogeneity among included studies using the Chi-squared test and $\mathrm{I}^{2}$ test. For a heterogeneity result of $\mathrm{I}^{2}>50 \%$ the random effects model was implemented; otherwise the fixed effects model was used to calculate pooled odds ratio (OR) and $95 \%$ confidence interval (CI) values [23]. A p-value < 0.05 was considered significant for statistical analysis. The allelic model ( 2 vs. 1$)$, dominant model $(22+12$ vs. 11$)$, and recessive model $(22$ vs. $12+11)$ were calculated to evaluate the association between TLR4 polymorphisms and OAG [24]. In order to detect potential publication bias, Begg's and Egger's tests were calculated using Stata (version 14; StataCorp, College Station, Texas).

\section{Results}

According to the literature search strategy, eight studies were included in this meta-analysis (Figure 1). Relevant features of the included studies were consistent in the two review authors and the results were summarized in Table 1. Among the enrolled studies, Takano et al. [16] conducted a multicenter study about TLR4 genes and included four study groups, so we separately compared the two OAG patient groups (NTG group and POAG group) with the normal control group. The study populations came from different countries: Japan, Korea, China, Saudi Arabia, and Mexico. According to the NOS scoring system, the two reviewer authors rated the same scores and all the selected studies in our meta-analysis were considered to be of high quality. Furthermore, all the included studies have shown that genotype distributions of all SNPs in the control groups were consistent with HWE in the original papers.

A total of 10 SNPs were involved in the included studies: rs7037117, rs10759930, rs1927914, rs1927911, rs12377632, rs2149356, rs11536889, rs7045953, rs4986790, and rs4986791. Among 10 SNPs on the TLR4 gene, two SNPs located on the 5' untranslated region (UTR) (rs10759930 and rs1927914), and three intronic SNPs (rs1927911, rs12377632, and rs2149356), two nonsynonymous exonic SNPs (rs4986790, rs4986791), and three SNPs located on the 3' UTR (rs11536889, rs7037117, and rs7045953). The locations of the above SNPs are shown in Figure 2. As for rs4986790 and rs4986791, only two research teams from Saudi Arabia and Mexico focused on 


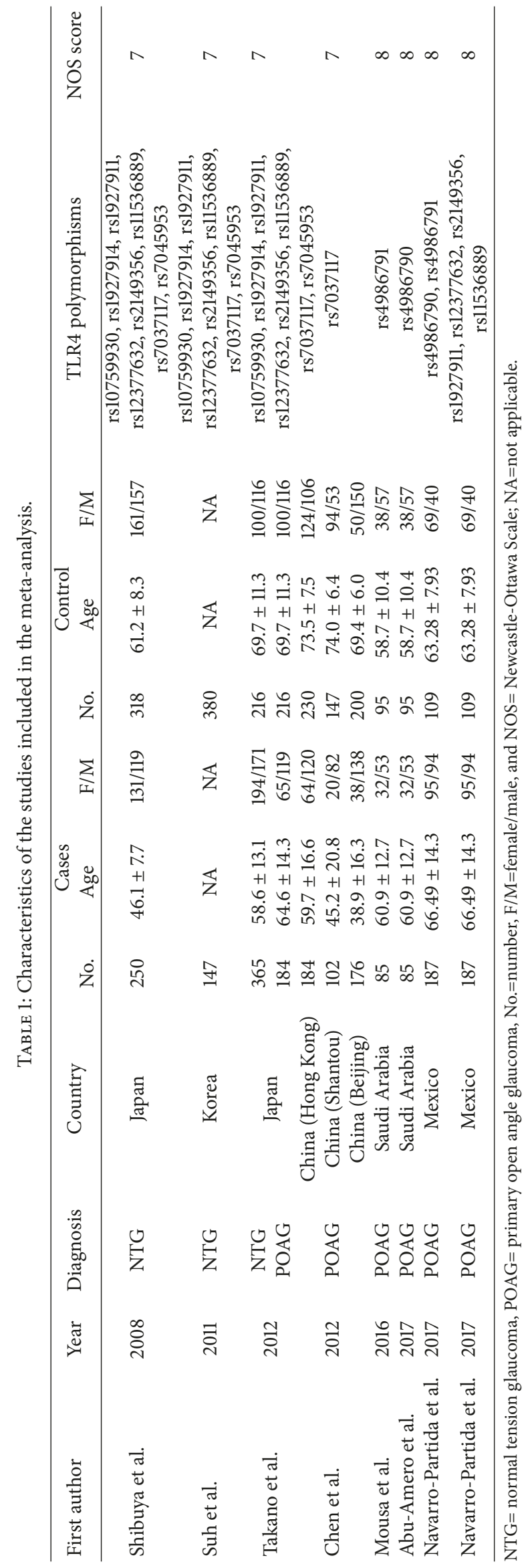




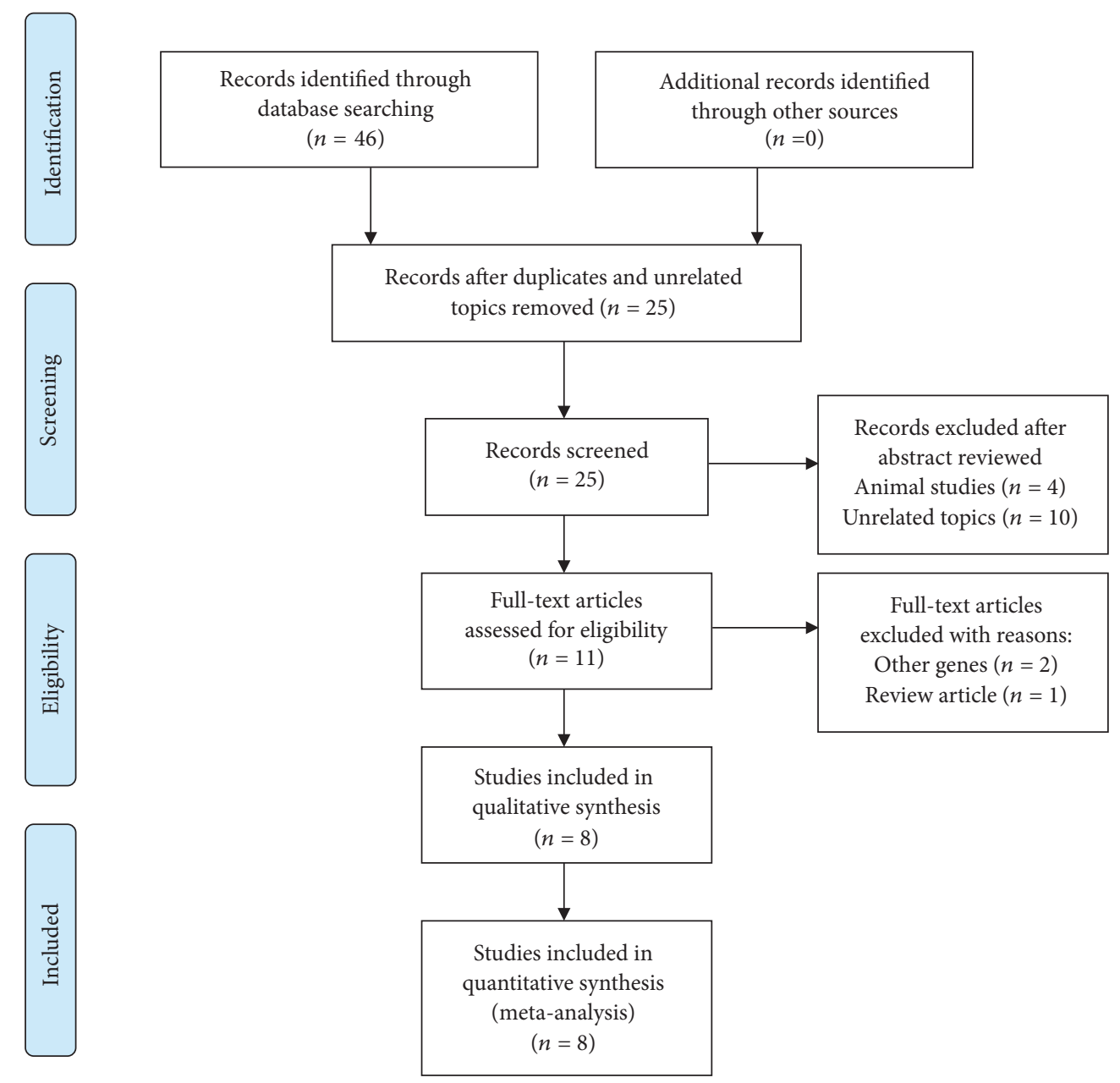

FIGURE 1: PRISMA flow diagram of the selection process for studies investigating the association between TLR 4 polymorphisms and open angle glaucoma.

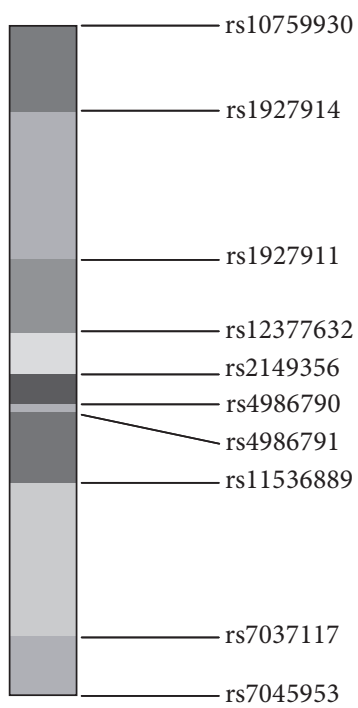

FIGURE 2: The genetic locations of 10 SNPs of the TLR4 gene. Two SNPs (rs10759930 and rs1927914) located on the 5' untranslated region. Three SNPs (rs1927911, rs12377632, and rs2149356) were in the intronic region and two SNPs (rs4986790, rs4986791) were in the nonsynonymous exonic region. Three SNPs (rs11536889, rs7037117, and rs7045953) located on the 3' untranslated region. 


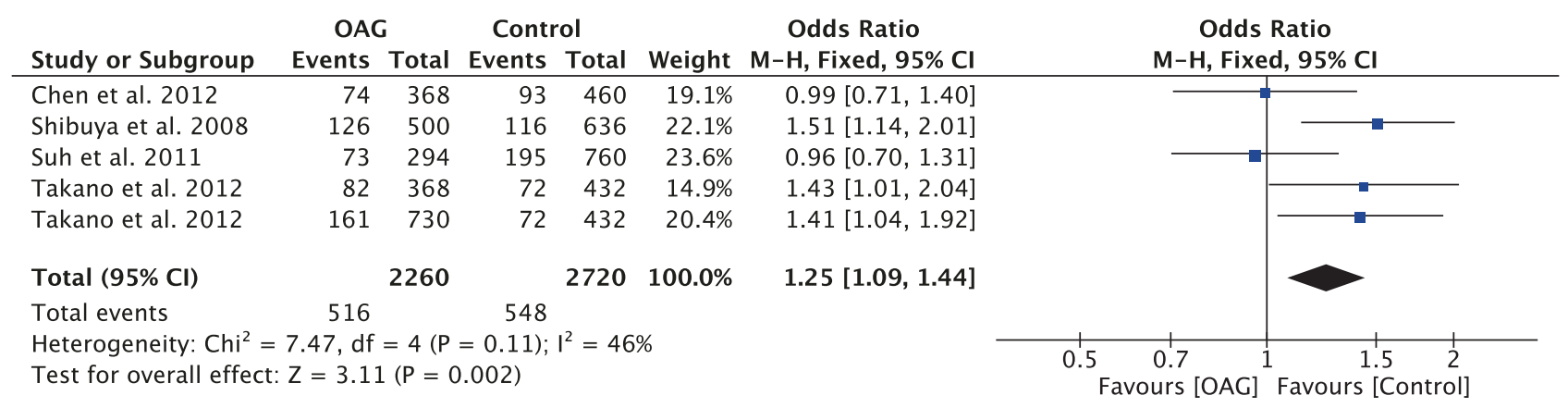

(a)

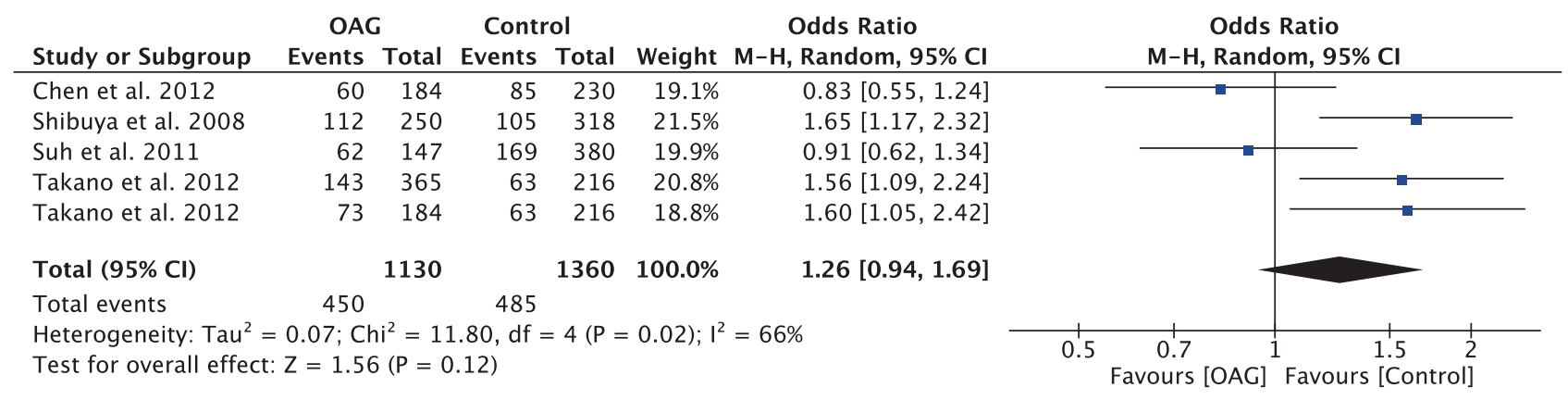

(b)

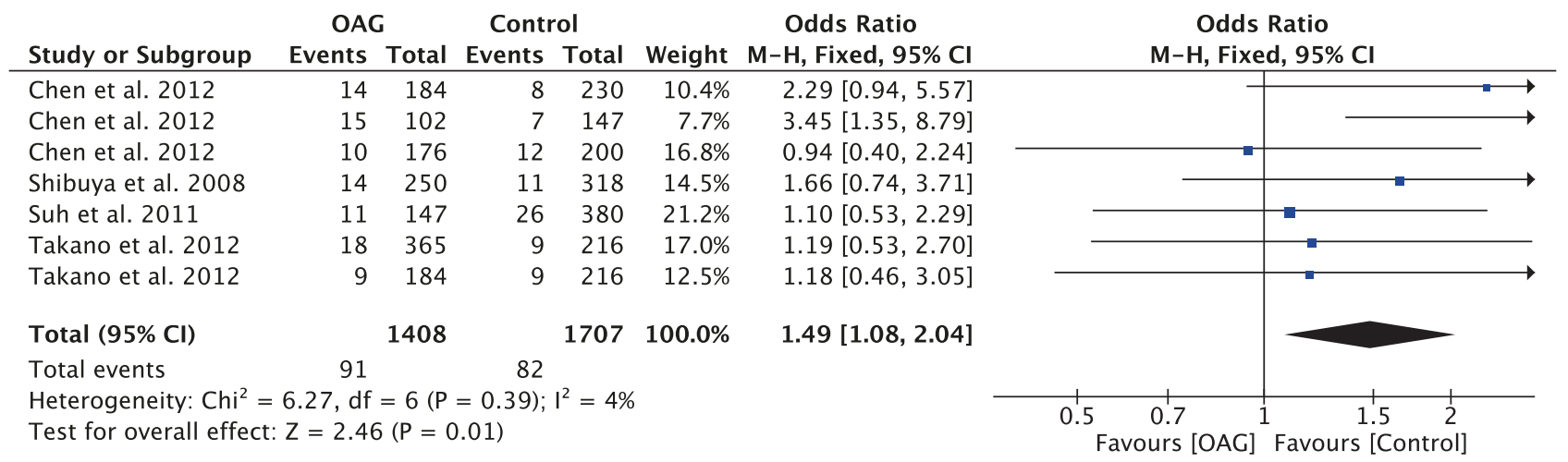

(c)

FIgure 3: Forest plot of the association between TLR4 rs7037117 polymorphism and open angle glaucoma for all five models. (a) Allelic model, (b) dominant model, and (c) recessive model.

these SNPs. Considering the ethnic differences and the limited number of studies, quantitative meta-analyses were not performed.

The association strengths between TLR polymorphisms and OAG are presented in Table 2. Stratification analyses were further performed based on ethnicity or glaucoma subtype. Combined data revealed that TLR4 rs7037117 polymorphism had significant associations with increased risk of OAG in allelic model (OR=1.25; 95\%CI: $1.09-1.44 ; \mathrm{P}=0.002)$ and recessive model $(\mathrm{OR}=1.49 ; 95 \% \mathrm{CI}$ : $1.08-2.04 ; \mathrm{P}=0.01)$ (Figure 3). Stratification analyses also suggested that the role of GG genotype increased the risk of OAG in Asian patients, especially in POAG patients (OR=1.71; 95\%CI: 1.10 $2.66 ; \mathrm{P}=0.02$ ).
With regard to rs10759930, rs12377632, and rs2149356, the meta-analysis results showed significant differences in all genetic models (all $\mathrm{P}<0.05$ ) (Figures $4-6$ ), indicating that the mutant allele carriers had an increased frequency in OAG patients; thus we had reason to believe that these SNPs were associated with increased risk of OAG. However, there was significant heterogeneity among the available studies. When stratified by ethnicity, we detected that rs10759930 increased the OAG risk in Asians, while rs12377632 and rs2149356 increased the risk in both Asians and Mexicans. When stratified according to the subtype of glaucoma, significant associations were found in POAG patients rather than NTG patients, whereas, for rs1927914, rs7045953, and rs11536889, no significant associations were identified for 


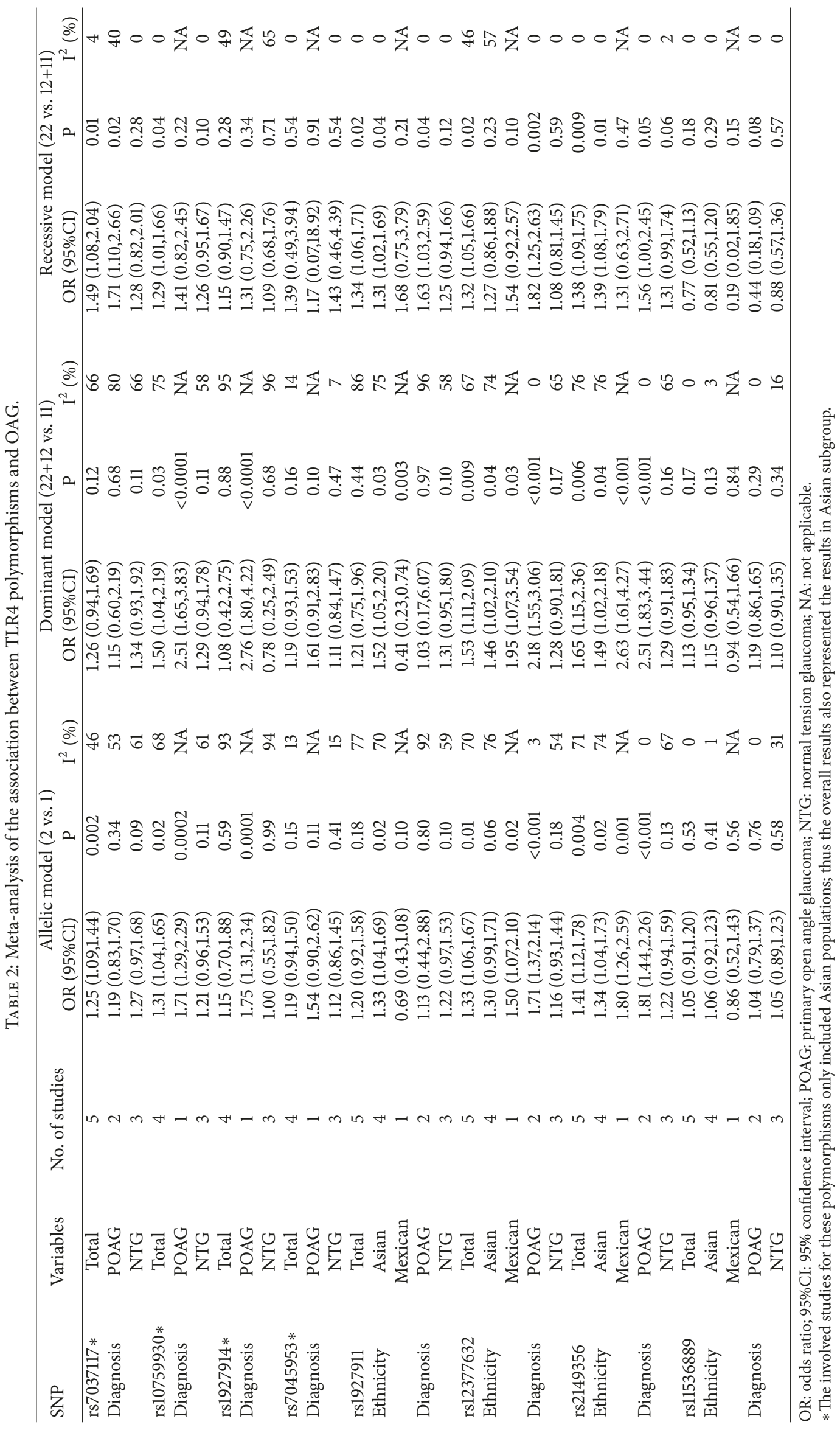




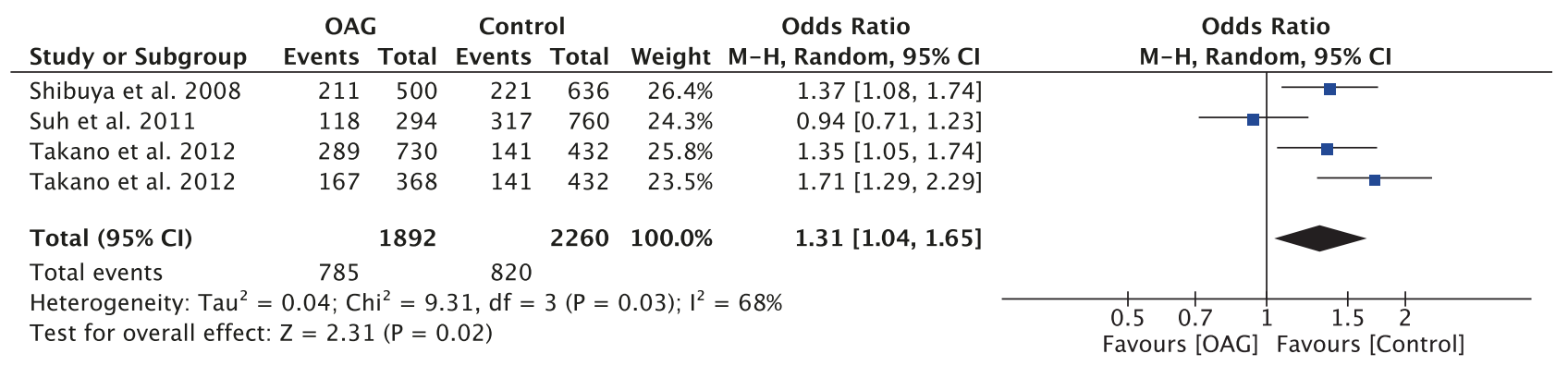

(a)

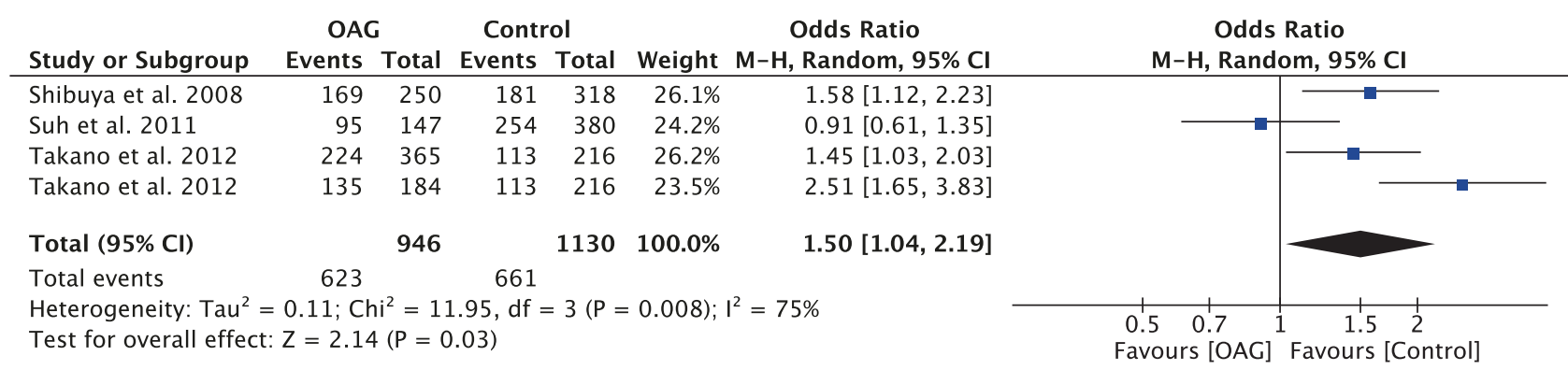

(b)

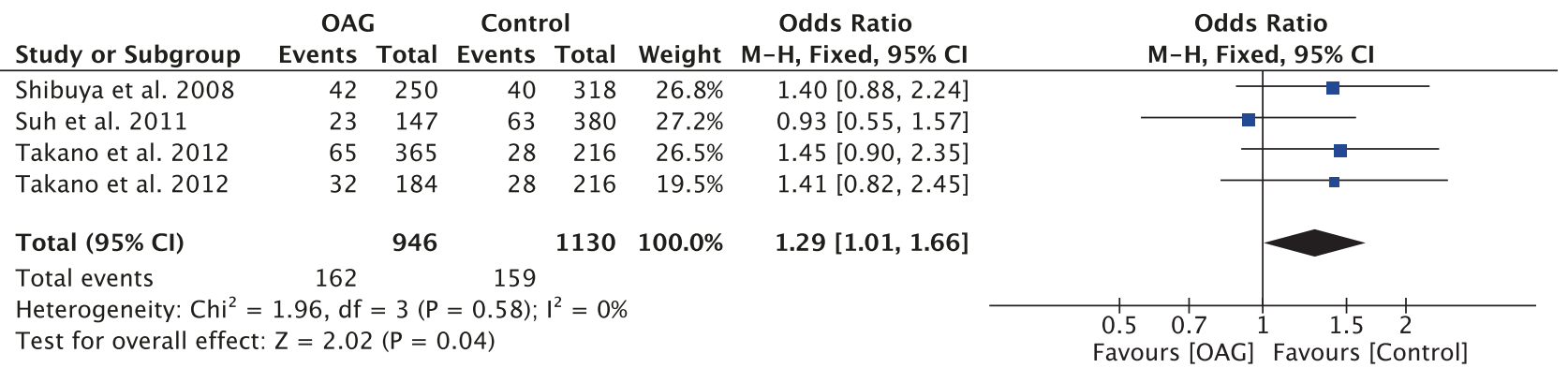

(c)

FIGURE 4: Forest plot of the association between TLR4 rs10759930 polymorphism and open angle glaucoma for all five models. (a) Allelic model, (b) dominant model, and (c) recessive model.

TABLE 3: Begg's and Egger's test for publication bias in the meta-analysis of the association between TLR4 polymorphisms and OAG.

\begin{tabular}{|c|c|c|c|c|c|c|c|}
\hline \multirow[t]{2}{*}{ SNP } & \multirow[t]{2}{*}{ Alleles (1/2) } & \multicolumn{2}{|c|}{$\begin{array}{l}\text { Allelic model } \\
\text { (2 vs. } 1)\end{array}$} & \multicolumn{2}{|c|}{$\begin{array}{l}\text { dominant model } \\
\qquad(22+12 \text { vs. } 11)\end{array}$} & \multicolumn{2}{|c|}{$\begin{array}{l}\text { recessive model } \\
(22 \text { vs. } 12+11)\end{array}$} \\
\hline & & P (Begg) & $\mathrm{P}$ (Egger) & P (Begg) & $\mathrm{P}$ (Egger) & P (Begg) & $\mathrm{P}$ (Egger) \\
\hline rs7037117 & $\mathrm{A} / \mathrm{G}$ & 0.462 & 0.567 & 0.221 & 0.372 & 0.368 & 0.233 \\
\hline rs10759930 & $\mathrm{T} / \mathrm{C}$ & 1 & 0.869 & 0.734 & 0.648 & 0.734 & 0.642 \\
\hline rs1927914 & $\mathrm{A} / \mathrm{G}$ & 0.734 & 0.734 & 0.734 & 0.658 & 0.308 & 0.481 \\
\hline rs7045953 & $\mathrm{A} / \mathrm{G}$ & 1 & 0.936 & 1 & 0.925 & 0.089 & 0.335 \\
\hline rs1927911 & G/A & 1 & 0.443 & 0.462 & 0.529 & 0.462 & 0.428 \\
\hline rs12377632 & $\mathrm{C} / \mathrm{T}$ & 0.806 & 0.576 & 0.806 & 0.597 & 1 & 0.873 \\
\hline rs2149356 & $\mathrm{G} / \mathrm{T}$ & 0.462 & 0.400 & 0.462 & 0.285 & 1 & 0.991 \\
\hline rs11536889 & $\mathrm{G} / \mathrm{C}$ & 0.806 & 0.698 & 0.462 & 0.923 & 0.806 & 0.323 \\
\hline
\end{tabular}

any polymorphisms in overall analyses in any genetic model (all $\mathrm{P}>0.05$ ) (Figures 7-9). Furthermore, the association of rs1927911 with OAG risk was found to be significant in recessive models ( $\mathrm{OR}=1.34$; 95\%CI: 1.06-1.71; $\mathrm{P}=0.02$ ) (Figure 10). Subgroup analysis indicated that the GG genotype might exert an increased risk in Asian POAG patients (Asian: $\mathrm{OR}=1.31$; 95\%CI: 1.02-1.69; $\mathrm{P}=0.04$; POAG: $\mathrm{OR}=1.63$; 95\%CI: 1.03-2.59; $\mathrm{P}=0.04$ ).

Funnel plots were not constructed to assess the publication bias due to relatively limited number of studies. Instead, 


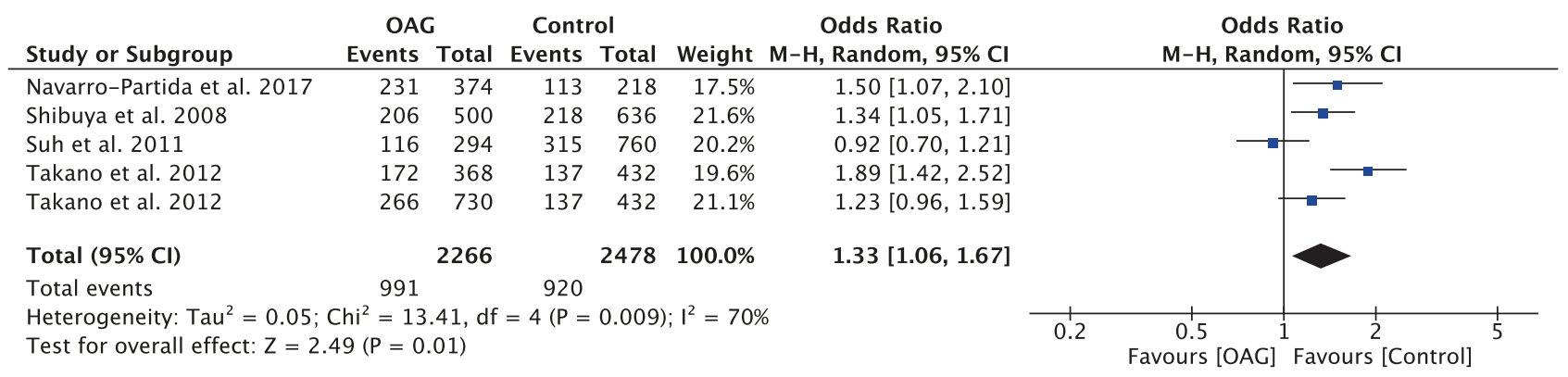

(a)

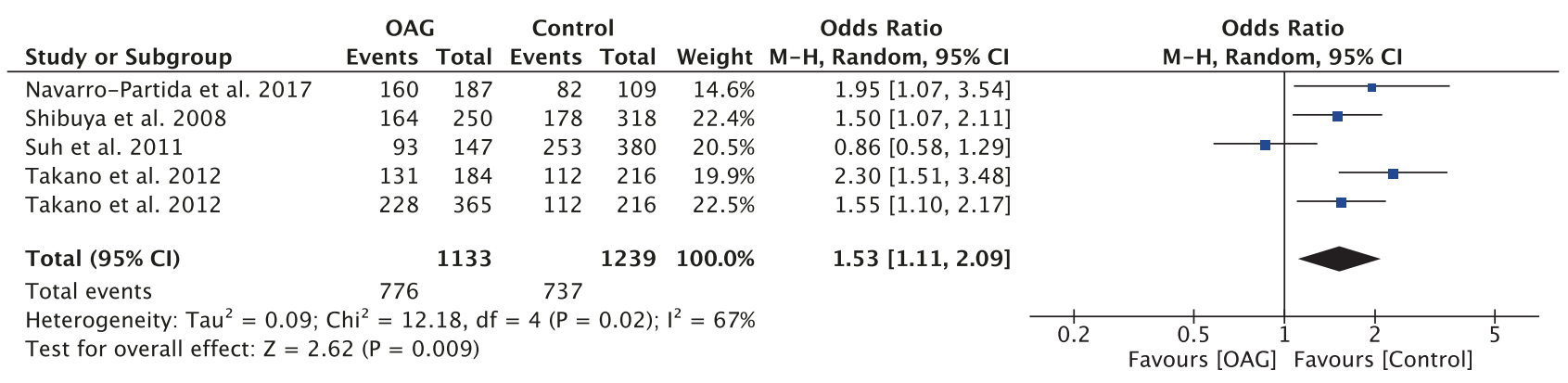

(b)

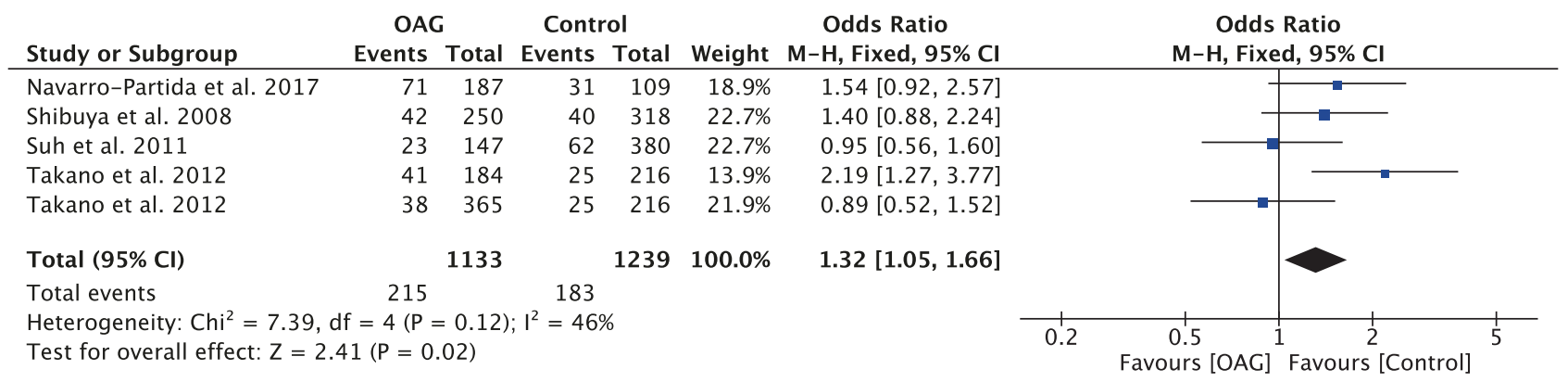

(c)

FIGURE 5: Forest plot of the association between TLR4 rs12377632 polymorphism and open angle glaucoma for all five models. (a) Allelic model, (b) dominant model, and (c) recessive model.

Begg's test and Egger's test were adopted. The results of these genotype analyses showed no obvious publication bias (all $\mathrm{P}>0.05$ ) (Table 3).

\section{Discussion}

Open-angle glaucoma is traditionally considered to be a multifactorial disease with strong evidence implicating a significant heritable component. Genetic linkage studies have so for identified more than 20 gene loci that contribute to the genetic risk of POAG, such as myocilin (MYOC), optineurin (OPTN), caveolins 1 and 2 (CAV1/CAV2), cyclin-dependent kinase inhibitor $2 \mathrm{~B}$ antisense $(\mathrm{CDKN} 2 \mathrm{~B})$, and growth arrestspecific 7 (GAS7) $[4,25]$. TLRs are important contributors to the innate immune system and imbalance of both proapoptotic and protective regulation may lead to the degeneration of the RGCs in glaucoma, especially TLR4. Currently, studies about TLR4 polymorphisms in the ocular diseases were mainly focused on age-related macular degeneration (AMD), diabetic retinopathy (DR), and OAG. The role of TLR4 polymorphisms seemed to be negative and awaited further investigations in AMD patients [26-28], whereas some scholars associated TLR4 variants with susceptibility of DR [29-31]. However, studies concerning the association between TLR4 polymorphisms and OAG have presented contradictory conclusions.

In the present study, we undertook a systematic review and meta-analysis of associations between TLR4 polymorphisms and the presence of OAG, trying to figure out whether TLR4 SNPs could be regarded as a novel potential candidate genetic risk factor for OAG. TLR4 rs7037117, rs1927911, rs10759930, rs12377632, and rs2149356 might contribute to OAG susceptibility. Meta-analysis of the TLR4 rs1927914, 


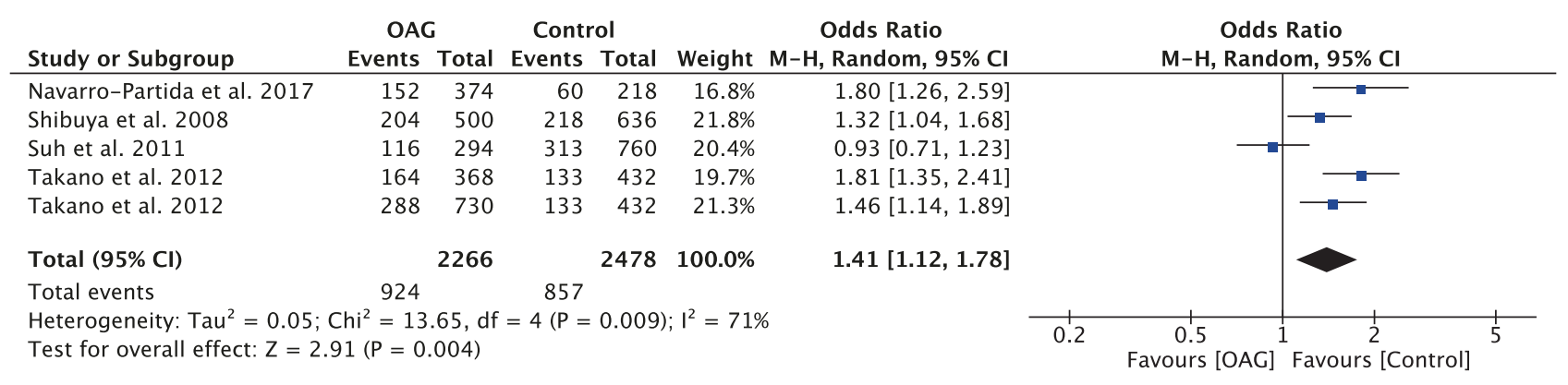

(a)

\begin{tabular}{|c|c|c|c|c|c|c|c|c|c|c|}
\hline Study or Subgroup & \multicolumn{2}{|c|}{ OAG } & \multicolumn{2}{|c|}{ Control } & Weight & Odds Ratio & \multicolumn{3}{|c|}{$\begin{array}{c}\text { Odds Ratio } \\
\mathrm{M}-\mathrm{H}, \text { Random, } 95 \% \mathrm{Cl}\end{array}$} & \\
\hline Navarro-Partida et al. 2017 & 126 & 187 & 48 & 109 & $17.8 \%$ & $2.63[1.61,4.27]$ & & & & \\
\hline Shibuya et al. 2008 & 163 & 250 & 178 & 318 & $21.3 \%$ & $1.47[1.05,2.07]$ & & & - & \\
\hline Takano et al. 2012 & 226 & 365 & 109 & 216 & $21.4 \%$ & $1.60[1.14,2.24]$ & & & - & \\
\hline Takano et al. 2012 & 131 & 184 & 109 & 216 & $19.5 \%$ & $2.43[1.60,3.68]$ & & & & \\
\hline Total $(95 \% \mathrm{Cl})$ & & 1133 & & 1239 & $100.0 \%$ & $1.65[1.15,2.36]$ & & & & \\
\hline Total events & 739 & & 696 & & & & & & & \\
\hline $\begin{array}{l}\text { Heterogeneity: } \mathrm{Tau}^{2}=0.13 \text {; } \\
\text { Test for overall effect: } \mathrm{Z}=2\end{array}$ & $\begin{array}{l}-h i^{2}=16 \\
73(P=0\end{array}$ & $\begin{array}{l}94, \mathrm{df} \\
.006)\end{array}$ & $=4(P=$ & $0.002)$ & $; I^{2}=76 \%$ & & 0.2 & $\begin{array}{ll}0.5 & 1 \\
\text { vours [OAG] }\end{array}$ & $\begin{array}{c}2 \\
\text { Favours }[\mathrm{C}\end{array}$ & \\
\hline
\end{tabular}

(b)

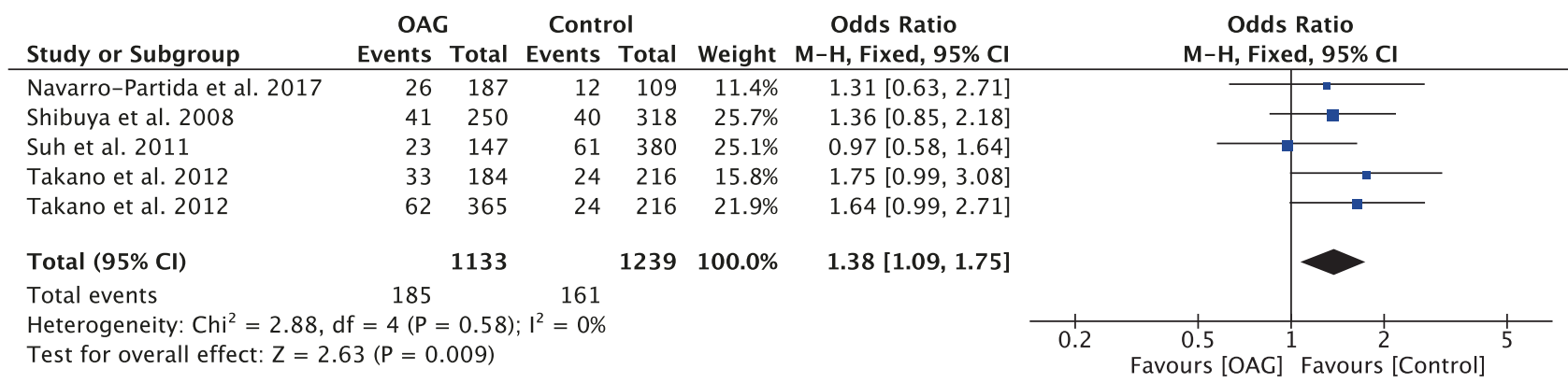

(c)

FiguRE 6: Forest plot of the association between TLR4 rs2149356 polymorphism and open angle glaucoma for all five models. (a) Allelic model, (b) dominant model, and (c) recessive model.

rs11536889, and rs7045953 failed to reveal any significant associations with OAG. Since previous results of different studies have presented that ethnic differences may affect genetic predisposition to OAG [32-34], we also conducted subgroup analysis. When stratified by ethnicity, we detected that rs7037117, rs10759930, and rs1927911 might increase the risk in Asians, while rs12377632 and rs2149356 seemed to increase the risk in Asians and Mexicans. Chen et al. [35] recently conducted a systematic review and meta-analysis of all reported gene polymorphisms associated with POAG, and the results showed a significant association in 20 SNPs, which also included TLR4 polymorphisms. Their analyses showed that rs1927911 and rs2149356 in the TLR4 gene indicated significant association with POAG in Asians, which was consistent with our results. But our study emphasized and described in detail that ethnicity was one influence factor of TLR4 polymorphisms causing the risk of OAG. The enrolled studies were mainly carried out in East Asia, suggesting OAG is a complex disease with many associated factors, such as the environmental factors like dietary habits and lifestyle. However, whether the role of TLR4 polymorphisms in OAG is ethnic specific remains to be elucidated. More studies from different ethnic background, such as Caucasian and African, are needed to further define this association. When stratified by the subtype of glaucoma, our results demonstrated that TLR4 polymorphisms may have a tendency to influence the phenotypic features in POAG patients, instead of NTG patients, indicating that the pathogenesis and effect of TLR4 may be different between POAG and NTG. Chaiwiang and Poyomtip [36] conducted a similar meta-analysis recently and six allelic models were examined in their analysis. One notable difference was that their results indicated that only rs1927911 correlated with NTG in the homozygous model ( $\mathrm{GG}$ vs. $\mathrm{AA} ; \mathrm{OR}=0.70 ; \mathrm{P}=0.025$ ), suggesting that individuals 


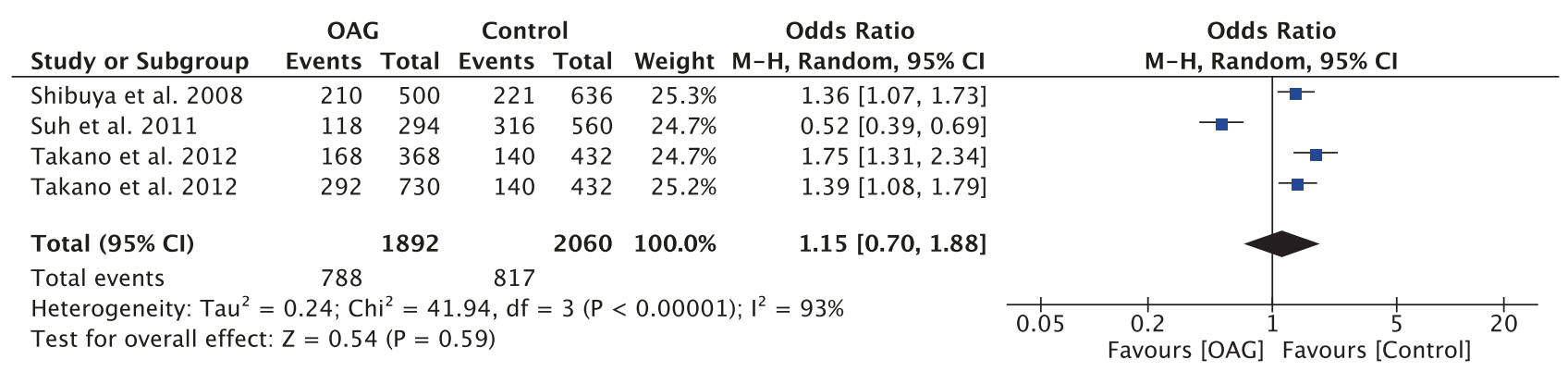

(a)

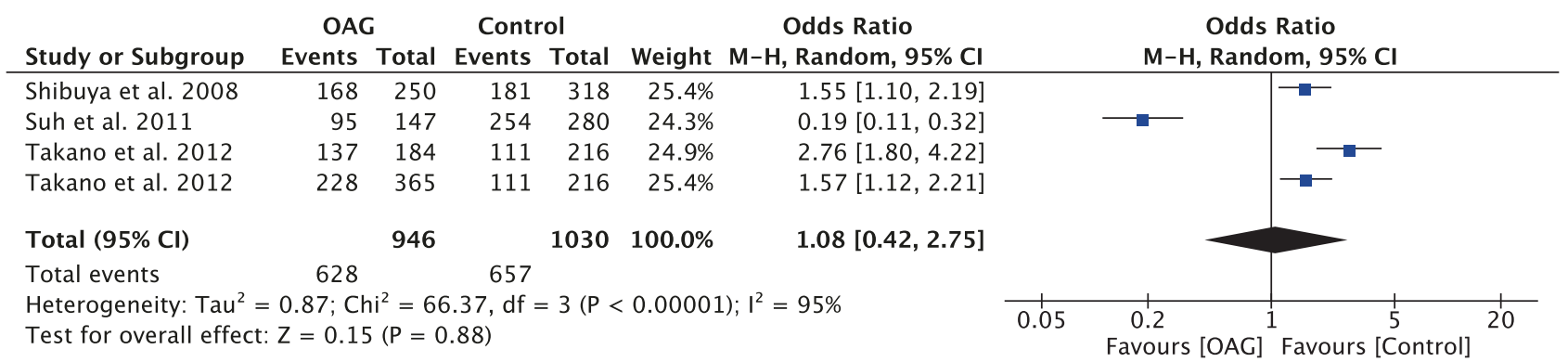

(b)

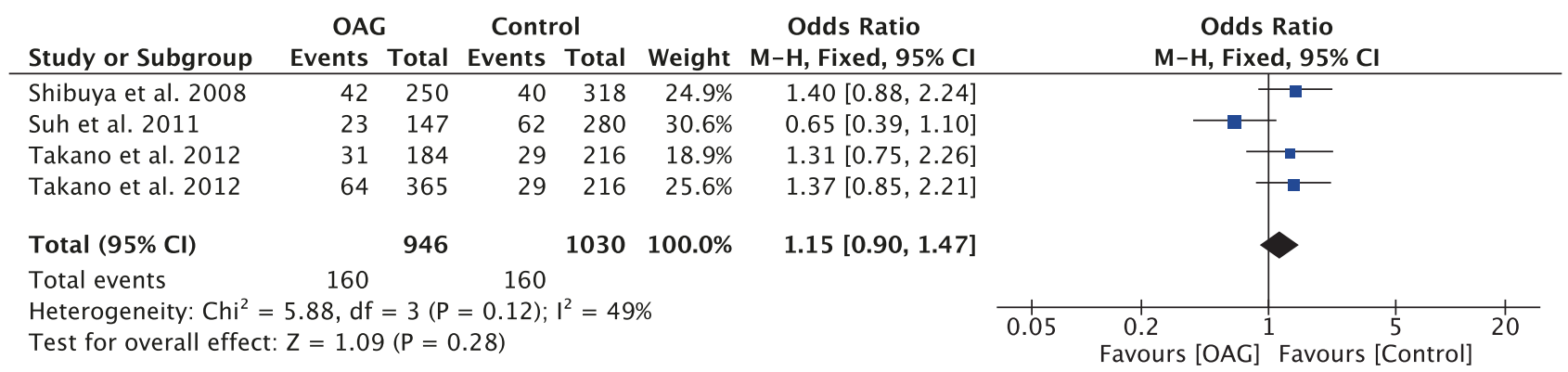

(c)

FIGURE 7: Forest plot of the association between TLR4 rs1927914 polymorphism and open angle glaucoma for all five models. (a) Allelic model, (b) dominant model, and (c) recessive model.

with the homozygous AA genotype exhibited increased risk of NTG when comparing with the GG homozygote. Further studies are required to provide supporting evidence. However, modest heterogeneity still existed in our estimates after we conducted stratification analyses. Thus, these results should be interpreted with caution.

TLR4 gene, located in chromosome 9q32-q33, participates in the activation of an inflammatory cascade through nuclear factor kappa-light-chain-enhancer of activated B cells $(\mathrm{NF}-\kappa \mathrm{B})$ [37]. The dysregulation of TLR4 signaling pathway during oxidative and ischemic injuries promotes axonal and neuronal loss. As is known to all, the mutations in 5'UTR can usually affect the expression of downstream gene by either translational regulation or impacting the cis-element binding of transcription factors. The sequence and structural features of the 3'UTR strongly influence the regulation of mRNA stability, translation, and localization. While the intronic SNPs do not have any direct influence on the conformation of the protein molecule, they are integral to gene expression regulation. Our meta-analysis results confirmed that certain mutations of some SNPs located on these sequences might increase the risk of OAG. Although the exact function of these TLR4 polymorphisms was not fully understood, there is a possibility that these SNPs might influence the mRNA stability and regulate the TLR4 gene expression, either the amount of TLR4 produced and/or relative levels of isoforms.

Polymorphisms of rs4986790 and rs4986791 in exon 3 are among the best-known and most often studied SNPs in TLR4 family. The genetic variation in the coding region of the TLR4 gene rs4986790 and rs4986791 could lead to variants in polypeptide chains; thus the coreceptor binding region would change and affect the signal transduction of the receptor in response to LPS stimulation. In other words, the missense mutation results in an amino acid substitution are associated with receptor hyporesponsiveness [38-40]. This might cause a dysfunction of the TLR4 molecule and interfere with the host immune system. Currently, two research teams from 


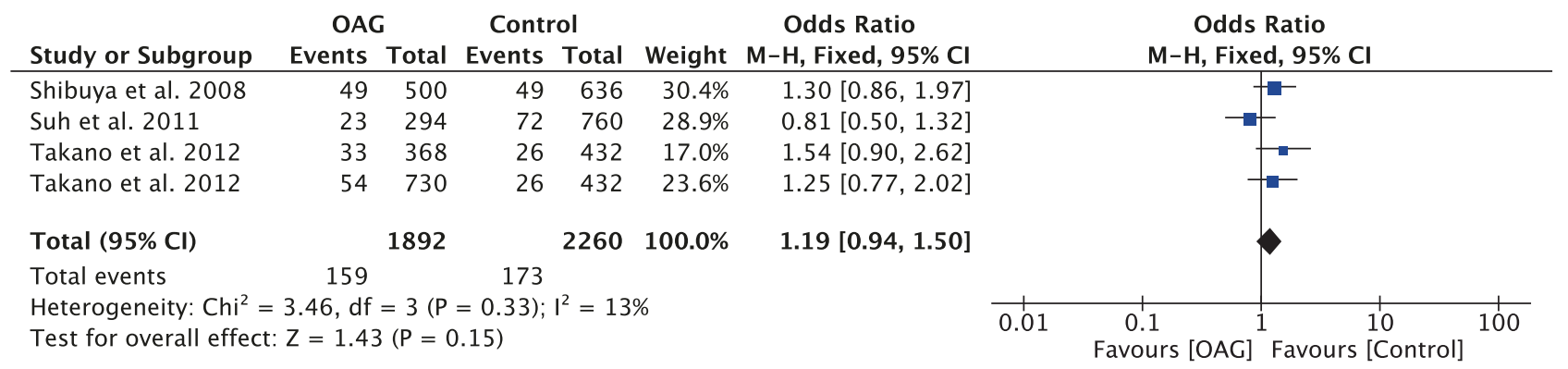

(a)

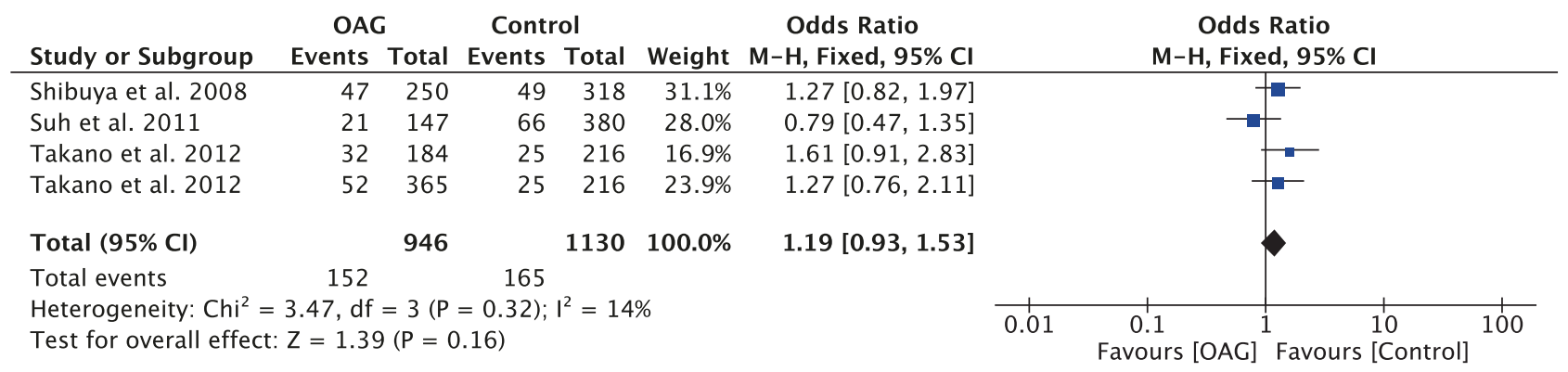

(b)

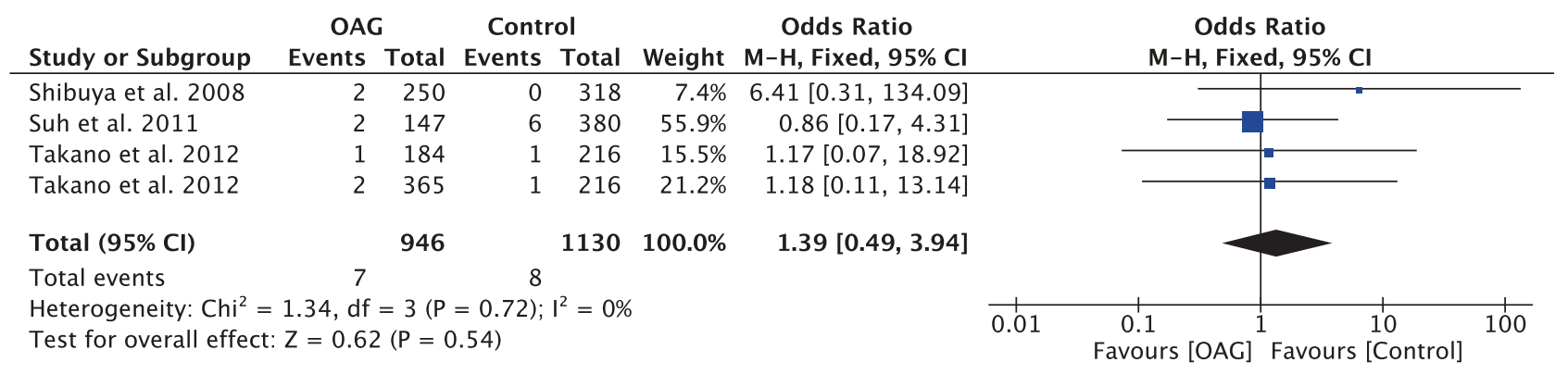

(c)

FIgURE 8: Forest plot of the association between TLR4 rs7045953 polymorphism and open angle glaucoma for all five models. (a) Allelic model, (b) dominant model, and (c) recessive model.

Saudi Arabia [18, 19] and Mexico [21] focused on rs4986790 and rs4986791 polymorphisms, only to yield inconsistent results. Confronting ethnic disparities, meta-analyses were not performed in these two SNPs. More studies should be performed in the future to assess these SNPs.

Nowadays, it is still not completely clear how TLR4 SNPs are associated with OAG, but a series of experimental evidence has addressed the role of TLR4 signaling in the pathophysiology of glaucoma. Luo et al. [13] demonstrated that TLR4 was upregulated in the retina of human glaucomatous eyes and the expression of TLR4 was prominently located on retinal microglia cells. TLR4 signaling was also identified in the regulation of the extracellular matrix in the trabecular meshwork [41, 42]. Morzaev et al. [10] revealed that TLR4 knockout mice had better preservation of RGCs after optic nerve crush, indicating that the TLR4-depedent pathway was involved in inducing the RGCs death. Furthermore, results from in vivo treatment experiments suggested that inhibition of TLR4-NF- $\kappa$ B pathways would be an effective approach to prevent the apoptotic cascade of RGCs in glaucoma [11, 12]. Future studies should unravel how the studied SNPs functionally contribute to OAG.

The present study has some limitations. First, the number of studies included in the systematic review might have been relatively small, especially in the stratification analyses, making the results tentative, which await further confirmation in replication in more study cohorts. Second, heterogeneity is a potential problem that may affect the interpretation of the results, since heterogeneity obviously existed among studies for some polymorphisms, even after subgroup analyses according to ethnicity and subtypes for OAG. Third, only Asian and Mexican populations were involved in the final meta-analysis. Additional ethnic groups should be enrolled due to ethnic differences in gene polymorphisms. Finally, OAG is a multifactor disease related with genetic and environment factors. However, the potential roles of genegene and gene-environment interactions were not taken into consideration. 


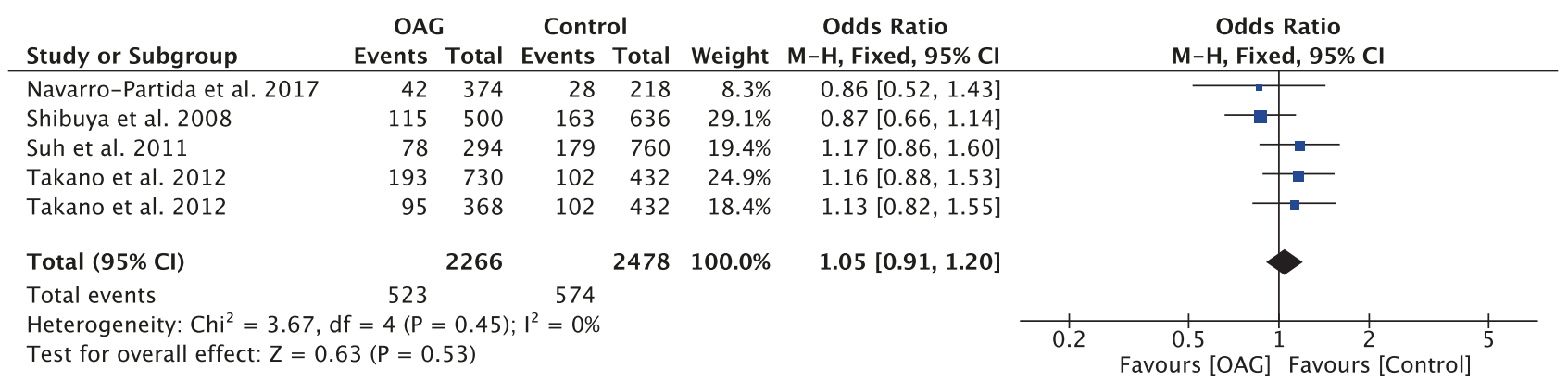

(a)

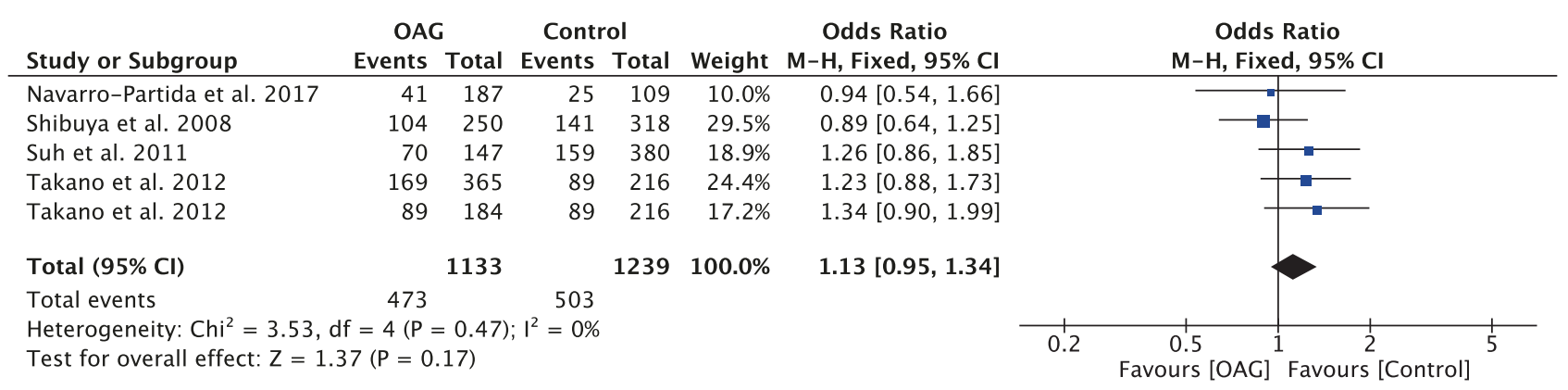

(b)

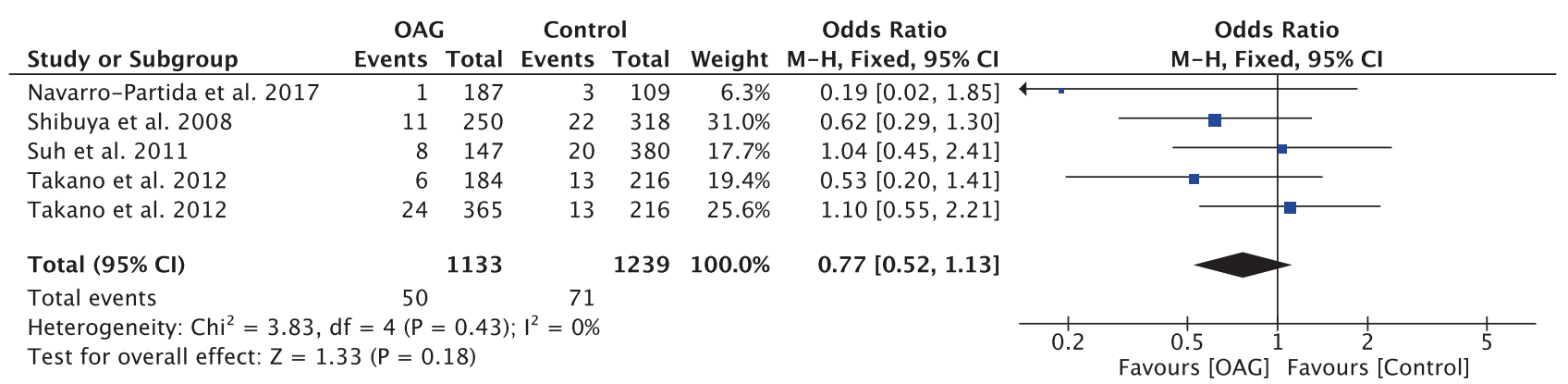

(c)

FIGURE 9: Forest plot of the association between TLR4 rs11536889 polymorphism and open angle glaucoma for all five models. (a) Allelic model, (b) dominant model, and (c) recessive model.

Nonetheless, our meta-analysis of case-control studies on TLR4 polymorphisms in OAG revealed that certain mutations of some TLR4 SNPs might increase the susceptibility of POAG in Asian and Mexican populations. However, TLR4 polymorphisms are still far from being candidate genetic biomarkers for OAG due to low statistical power and the presence of heterogeneity. The associations of TLR4 polymorphisms and their roles in the pathogenesis of OAG are still obscure and are not completely consistent in different ethnicities. More multicentric studies involving various ethnic groups and larger sample sizes are essential to provide a better ascertainment of the association between these TLR4 polymorphisms and OAG. Despite the tremendous progress in genes identified in glaucoma, further researches investigating gene polymorphisms are desiderated and expected to better understand this complex disease and help define disease specific targets, thus facilitating the development of diagnostic and therapeutic strategies.

\section{Conclusion}

The meta-analysis highlighted that certain mutations of some TLR4 polymorphisms might increase the susceptibility of OAG. However, TLR4 polymorphisms are still far from being candidate genetic biomarkers for OAG. Additional researches involving larger scale epidemiological studies are warranted to validate our results.

\section{Data Availability}

All data are fully available in the paper without restriction.

\section{Conflicts of Interest}

The authors declare that there was no funding support or conflicting interest regarding the publication of this paper. 


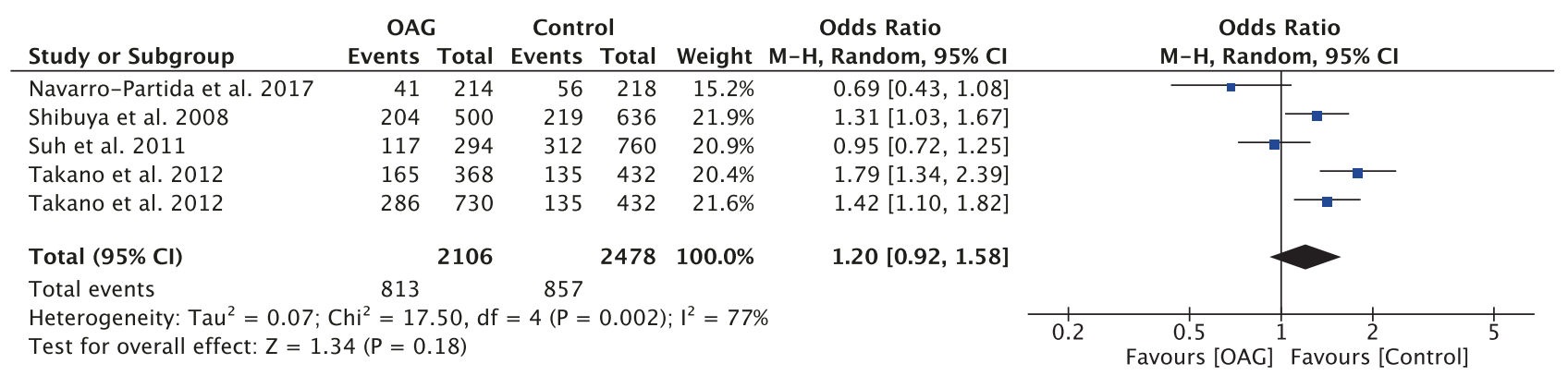

(a)

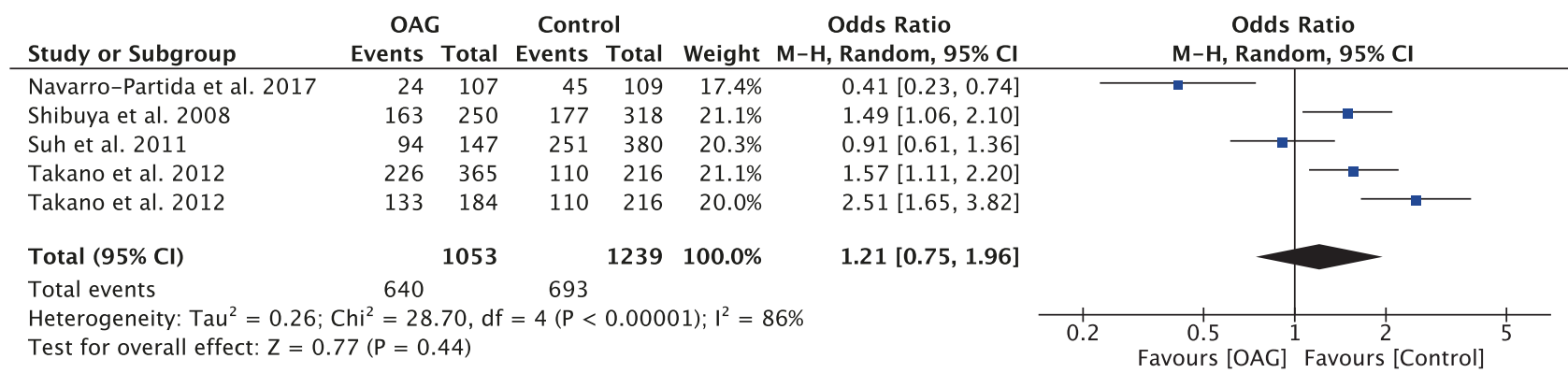

(b)

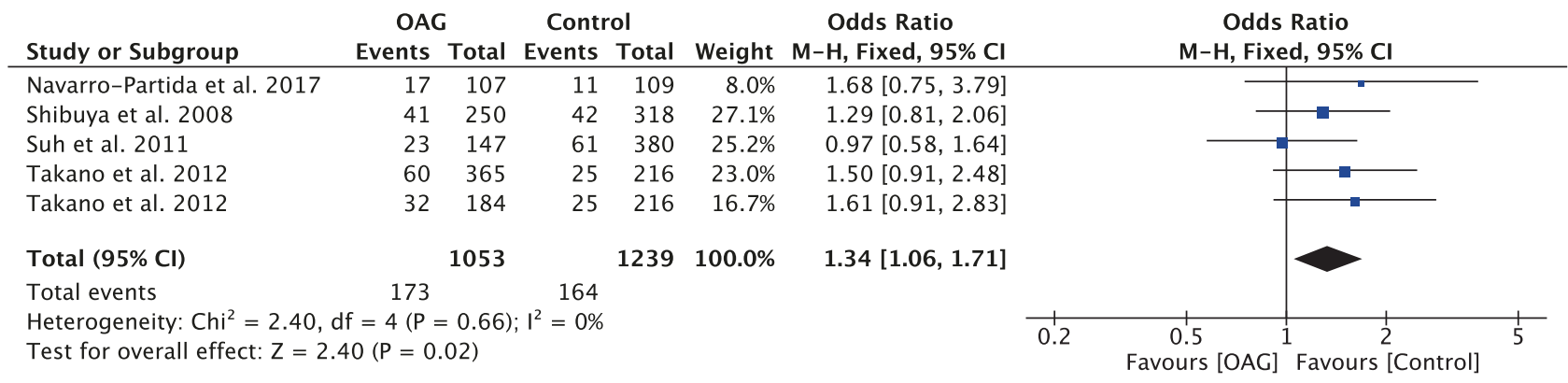

(c)

FIGURE 10: Forest plot of the association between TLR4 rs1927911 polymorphism and open angle glaucoma for all five models. (a) Allelic model, (b) dominant model, and (c) recessive model.

\section{Authors' Contributions}

Zhongjing Lin and Yisheng Zhong were responsible for the conceptualization of the study. Zhongjing Lin and Shouyue Huang did the literature search. Zhongjing Lin, Shouyue Huang, and Jun Sun undertook the data acquisition and analysis. Zhongjing Lin carried out the manuscript preparation. Bing Xie and Yisheng Zhong were responsible for the revision of manuscript. All authors have read and approved the final manuscript.

\section{References}

[1] Y.-C. Tham, X. Li, T. Y. Wong, H. A. Quigley, T. Aung, and C.Y. Cheng, "Global prevalence of glaucoma and projections of glaucoma burden through 2040: a systematic review and metaanalysis," Ophthalmology, vol. 121, no. 11, pp. 2081-2090, 2014.

[2] L. P. Doucette, A. Rasnitsyn, M. Seifi, and M. A. Walter, "The interactions of genes, age, and environment in glaucoma pathogenesis," Survey of Ophthalmology, vol. 60, no. 4, pp. 310$326,2015$.

[3] K. Abu-Amero, A. A. Kondkar, and K. V. Chalam, "An updated review on the genetics of primary open angle glaucoma," International Journal of Molecular Sciences, vol. 16, no. 12, pp. 28886-28911, 2015.

[4] J. L. Wiggs, "Glaucoma genes and mechanisms," Progress in Molecular Biology and Translational Science, vol. 134, pp. 315342, 2015.

[5] H. Wang, P. Sun, Y. Chen et al., "Research progress on human genes involved in the pathogenesis of glaucoma (Review)," Molecular Medicine Reports, 2018.

[6] J. Rieck, "The pathogenesis of glaucoma in the interplay with the immune system," Investigative Ophthalmology \& Visual Science, vol. 54, no. 3, pp. 2393-2409, 2013.

[7] G. Tezel, "The immune response in glaucoma: A perspective on the roles of oxidative stress," Experimental Eye Research, vol. 93, no. 2, pp. 178-186, 2011.

[8] G. Trinchieri and A. Sher, "Cooperation of Toll-like receptor signals in innate immune defence," Nature Reviews Immunology, vol. 7, no. 3, pp. 179-190, 2007. 
[9] W. Q. Xu and Y. S. Wang, “The role of Toll-like receptors in retinal ischemic diseases," International Journal of Ophthalmology, vol. 9, no. 9, pp. 1343-1351, 2016.

[10] D. Morzaev, J. D. Nicholson, T. Caspi, S. Weiss, E. Hochhauser, and N. Goldenberg-Cohen, "Toll-like receptor-4 knockout mice are more resistant to optic nerve crush damage than wildtype mice," Clinical \& Experimental Ophthalmology, vol. 43, no. 7, pp. 655-665, 2015.

[11] Y. Xu, B. Yang, Y. Hu et al., "Wogonin prevents TLR4-NF- $\kappa$ Bmedicated neuro-inflammation and improves retinal ganglion cells survival in retina after optic nerve crush," Oncotarget, vol. 7, no. 45, pp. 72503-72517, 2016.

[12] Y. Nakano, M. Shimazawa, K. Ojino et al., “Toll-like receptor 4 inhibitor protects against retinal ganglion cell damage induced by optic nerve crush in mice," Journal of Pharmacological Sciences, vol. 133, no. 3, pp. 176-183, 2017.

[13] C. Luo, X. Yang, A. D. Kain, D. W. Powell, M. H. Kuehn, and G. Tezel, "Glaucomatous tissue stress and the regulation of immune response through glial toll-like receptor signaling," Investigative Opthalmology \& Visual Science, vol. 51, no. 11, pp. 5697-5707, 2010.

[14] E. Shibuya, A. Meguro, M. Ota et al., "Association of tolllike receptor 4 gene polymorphisms with normal tension glaucoma," Investigative Ophthalmology \& Visual Science, vol. 49, no. 10, pp. 4453-4457, 2008.

[15] W. Suh, S. Kim, C. S. Ki, and C. Kee, "Toll-like Receptor 4 gene polymorphisms do not associate with normal tension glaucoma in a Korean population," Molecular Vision, vol. 17, no. 255-257, pp. 2343-2348, 2011.

[16] Y. Takano, D. Shi, A. Shimizu et al., "Association of Toll-like receptor 4 gene polymorphisms in Japanese subjects with primary open-angle, normal-tension, and exfoliation glaucoma," American Journal of Ophthalmology, vol. 154, no. 5, pp. 825832.el, 2012.

[17] L. J. Chen, P. O. Tam, D. Y. Leung et al., "SNP rs1533428 at 2p16.3 as a marker for late-onset primary open- angle glaucoma," Molecular Vision, vol. 18, no. 167-168, pp. 1629-1639, 2012.

[18] A. Mousa, A. A. Kondkar, S. A. Al-Obeidan et al., "Lack of association between polymorphism rs4986791 in TLR4 and primary open-angle glaucoma in a Saudi cohort," Genetic Testing and Molecular Biomarkers, vol. 20, no. 9, pp. 556-559, 2016.

[19] K. K. Abu-Amero, A. A. Kondkar, A. Mousa et al., "Analysis of toll-like receptor rs4986790 polymorphism in Saudi patients with primary open angle glaucoma," Ophthalmic Genetics, vol. 38, no. 2, pp. 133-137, 2016.

[20] J. Navarro-Partida, B. Alvarado Castillo, A. B. Martinez-Rizo, R. Rosales-Diaz, J. B. Velazquez-Fernandez, and A. Santos, “ Association of single-nucleotide polymorphisms in non-coding regions of the TLR4 gene with primary open angle glaucoma in a Mexican population ," Ophthalmic Genetics, vol. 38, no. 4, pp. 325-329, 2017.

[21] J. Navarro-Partida, A. B. Martinez-Rizo, P. Ramirez-Barrera et al., "Association of Toll-like receptor 4 single-nucleotide polymorphisms Asp299Gly and Thr399Ile with the risk of primary open angle glaucoma," Graefe's Archive for Clinical and Experimental Ophthalmology, vol. 255, no. 5, pp. 995-1001, 2017.

[22] A. Stang, "Critical evaluation of the Newcastle-Ottawa scale for the assessment of the quality of nonrandomized studies in metaanalyses," European Journal of Epidemiology, vol. 25, no. 9, pp. 603-605, 2010.
[23] J. P. T. Higgins and S. G. Thompson, "Quantifying heterogeneity in a meta-analysis," Statistics in Medicine, vol. 21, no. 11, pp.15391558, 2002.

[24] S. Shim, J. Kim, W. Jung, I. Shin, and J. Bae, "Meta-analysis for genome-wide association studies using case-control design: application and practice," Epidemiology and Health, Article ID e2016058, 2016.

[25] S. F. Janssen, T. G. M. F. Gorgels, W. D. Ramdas et al., "The vast complexity of primary open angle glaucoma: disease genes, risks, molecular mechanisms and pathobiology," Progress in Retinal and Eye Research, vol. 37, pp. 31-67, 2013.

[26] D. D. Despriet, A. A. Bergen, J. E. Merriam et al., "Comprehensive analysis of the candidate genes CCL2, CCR2, and TLR4 in age-related macular degeneration," Investigative Opthalmology \& Visual Science, vol. 49, no. 1, pp. 364-371, 2008.

[27] M. Güven, B. Batar, T. Mutlu et al., “Toll-like receptors 2 and 4 polymorphisms in age-related macular degeneration," Current Eye Research, vol. 41, no. 6, pp. 856-861, 2015.

[28] A. Sarli, I. Skalidakis, A. Velissari et al., "Investigation of associations of ARMS2, CD14, and TLR4 gene polymorphisms with wet age-related macular degeneration in a Greek population," Clinical Ophthalmology, vol. 11, pp. 1347-1358, 2017.

[29] M. Buraczynska, I. Baranowicz-Gaszczyk, J. Tarach, and A. Ksiazek, "Toll-like receptor 4 gene polymorphism and early onset of diabetic retinopathy in patients with type 2 diabetes," Human Immunology, vol. 70, no. 2, pp. 121-124, 2009.

[30] K. Singh, S. Kant, V. K. Singh, N. K. Agrawal, S. K. Gupta, and K. Singh, "Toll-like receptor 4 polymorphisms and their haplotypes modulate the risk of developing diabetic retinopathy in type 2 diabetes patients," Molecular Vision, vol. 20, no. 5, pp. 704-713, 2014.

[31] Y. Xu, Z. Jiang, J. Huang, Q. Meng, P. Coh, and L. Tao, “The association between toll-like receptor 4 polymorphisms and diabetic retinopathy in Chinese patients with type 2 diabetes," British Journal of Ophthalmology, vol. 99, no. 9, pp. 1301-1305, 2015.

[32] Y. Guo, H. Zhang, X. Chen, X. Yang, W. Cheng, and K. Zhao, "Association of TP53 polymorphisms with primary open-angle glaucoma: a meta-analysis," Investigative Opthalmology \& Visual Science, vol. 53, no. 7, p. 3756, 2012.

[33] W. Huang, W. Wang, M. Zhou, and X. Zhang, "Association of single-nucleotide polymorphism rs4236601 near caveolin 1 and 2 with primary open-angle glaucoma: a meta-analysis," Clinical \& Experimental Ophthalmology, vol. 42, no. 6, pp. 515-521, 2014.

[34] M. Wu, X. Zhu, and J. Ye, "Associations of polymorphisms of LOXL1 gene with primary open-angle glaucoma: a metaanalysis based on 5,293 subjects," Molecular Vision, vol. 21, pp. 165-172, 2015.

[35] M. Chen, X. Yu, J. Xu et al., "Association of gene polymorphisms with primary open angle glaucoma: a systematic review and meta-analysis," Investigative Opthalmology \& Visual Science, vol. 60, no. 4, pp. 1105-1121, 2019.

[36] N. Chaiwiang and T. Poyomtip, “The association of toll-like receptor 4 gene polymorphisms with primary open angle glaucoma susceptibility: a meta-analysis," Bioscience Reports, vol. 39, no. 4, Article ID BSR20190029, 2019.

[37] G. L. Hold, S. Berry, K. A. Saunders et al., “The TLR4 D299G and T399I SNPs are constitutively active to up-regulate expression of Trif-dependent genes," PLoS ONE, vol. 9, no. 11, Article ID el11460, 2014. 
[38] N. C. Arbour, E. Lorenz, B. C. Schutte et al., "TLR4 mutations are associated with endotoxin hyporesponsiveness in humans," Nature Genetics, vol. 25, no. 2, pp. 187-191, 2000.

[39] C. Schmitt, A. Humeny, C.-M. Becker, K. Brune, and A. Pahl, "Polymorphisms of TLR4: Rapid genotyping and reduced response to lipopolysaccharide of TLR4 mutant alleles," Clinical Chemistry, vol. 48, no. 10, pp. 1661-1667, 2002.

[40] D. Jahantigh, S. Salimi, R. Alavi-Naini, A. Emamdadi, H. O. Osquee, and F. F. Mashhadi, "Association between TLR4 and TLR9 gene polymorphisms with development of pulmonary tuberculosis in Zahedan, Southeastern Iran," The Scientific World Journal, vol. 2013, Article ID 534053, 7 pages, 2013.

[41] A. Grybauskas, T. Koga, P. V. Kuprys et al., "ABCB1 transporter and Toll-like receptor 4 in trabecular meshwork cells," Molecular Vision, vol. 21, pp. 201-212, 2015.

[42] H. Hernandez, W. E. Medina-Ortiz, T. Luan, A. F. Clark, and C. M. McDowell, "Crosstalk between transforming growth factor beta- 2 and toll-like receptor 4 in the trabecular meshwork," Investigative Opthalmology \& Visual Science, vol. 58, no. 3, p. 1811, 2017. 


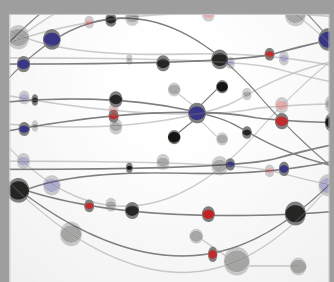

The Scientific World Journal
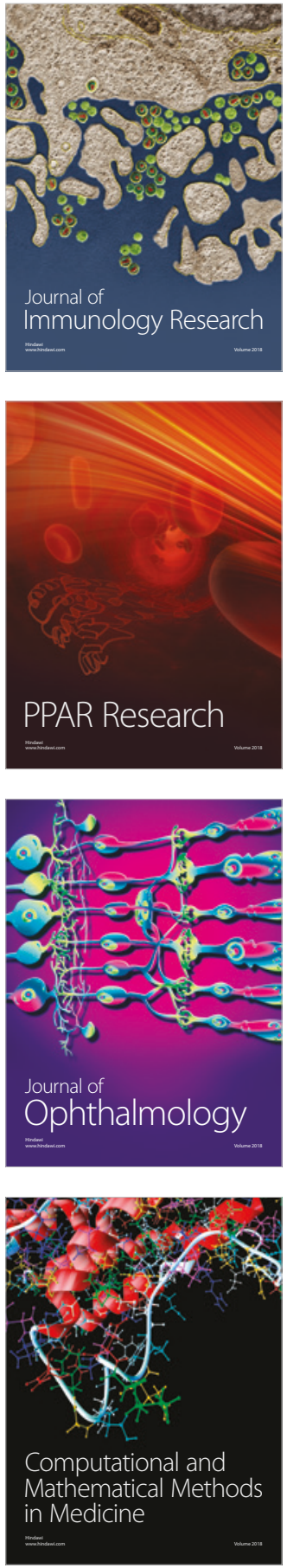

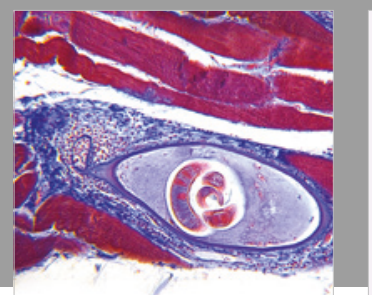

Gastroenterology Research and Practice

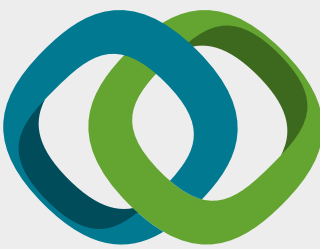

\section{Hindawi}

Submit your manuscripts at

www.hindawi.com
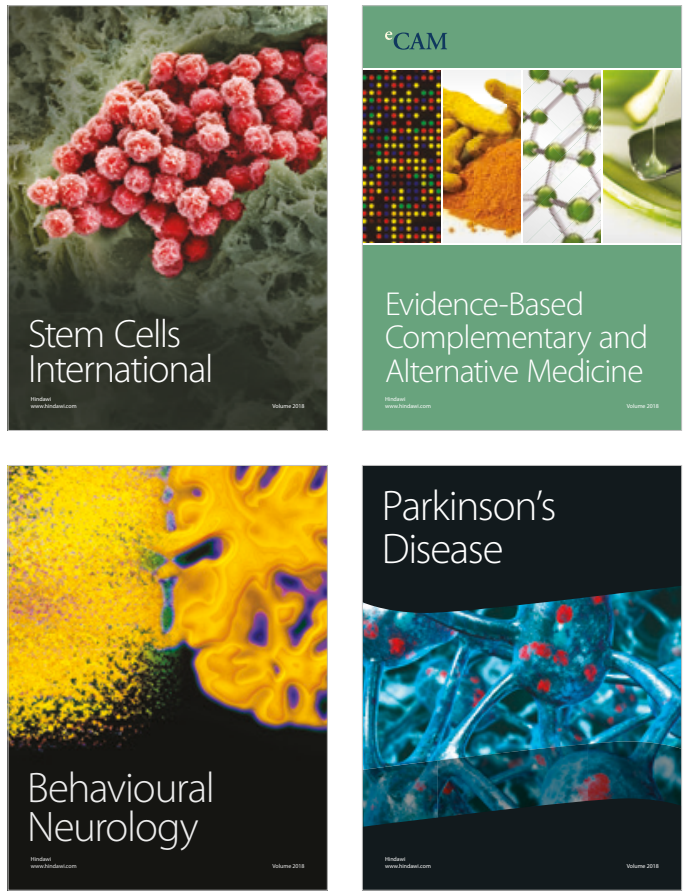

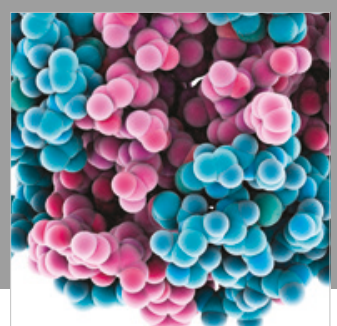

ournal of

Diabetes Research

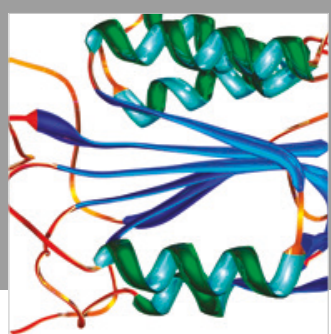

Disease Markers
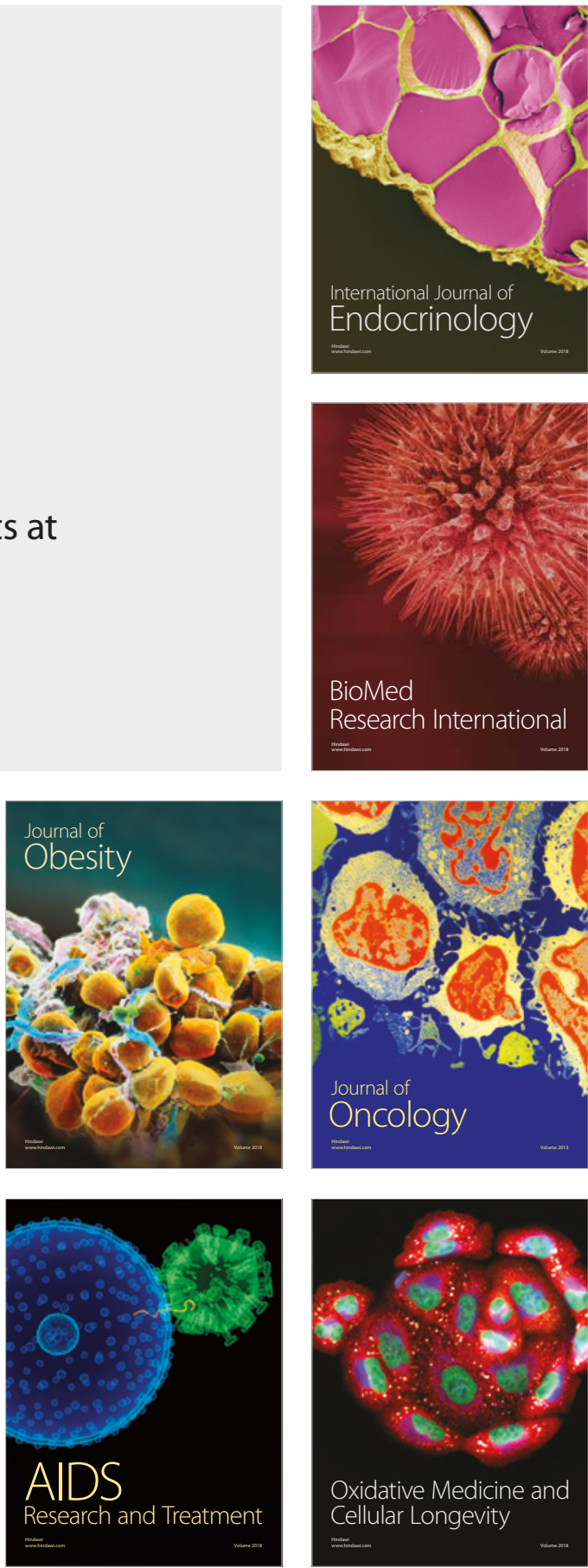